Research Paper

\title{
Ellagic acid exerts antitumor effects via the PI3K signaling pathway in endometrial cancer
}

\author{
Yizi Wang, Fang Ren, Bo Li, Zixuan Song, Peng Chen, Ling Ouyang ${ }^{\bowtie}$ \\ Department of Obstetrics and Gynecology, Shengjing Hospital of China Medical University, Shenyang 110004, People's Republic of China \\ $\triangle$ Corresponding author: Dr Ling Ouyang, Department of Obstetrics and Gynecology, Shengjing Hospital of China Medical University, Shenyang 110004, \\ China. Tel: +86-24-96615-41111; Fax: +86-24-83283488; E-mail: ouyl@sj-hospital.org \\ (C) Ivyspring International Publisher. This is an open access article distributed under the terms of the Creative Commons Attribution (CC BY-NC) license \\ (https://creativecommons.org/licenses/by-nc/4.0/). See http://ivyspring.com/terms for full terms and conditions.
}

Received: 2018.09.05; Accepted: 2019.04.29; Published: 2019.06.02

\begin{abstract}
Ellagic acid (EA) is a polyphenol found in several fruits and plants. EA has been reported to exert antitumor activity in many types of cancers. However, the effect and potential molecular mechanism of EA in endometrial cancer are still unclear. Therefore, the aim of this study was to explore the underlying antitumor function and targets by which EA inhibits endometrial cancer. By using multiplatform bioinformatics analysis tools, including DrugBank, STRING, WebGestalt and cBioPortal, the core targets of EA were identified as PIK3CA and PIK3R1. In addition, through transwell assays, EA was strongly found to inhibit cell invasion and migration. Based on CCK8 assays and flow cytometry, EA exhibited a suppressive effect on endometrial cancer cell proliferation by causing cell cycle arrest and inducing apoptosis. The results of real-time PCR confirmed that the expression of PIK3CA and PIK3R was decreased by EA. Furthermore, western blotting analysis demonstrated that EA inhibited PI3K phosphorylation, downregulating the expression of MMP9. In vivo, EA suppressed lung metastasis in $B A L B / c$ nude mice based on the SUVmax value determined from PET scans and HE staining. According to all these data, it comprehensively demonstrated the inhibitory effect of EA on endometrial cancer through bioinformatics analysis and experimental verification. Our findings suggest that EA may potentially be beneficial for treating endometrial cancer.
\end{abstract}

Key words: Bioinformatics, ellagic acid, DrugBank, WebGestalt, cBioPortal, endometrial cancer

\section{Introduction}

Endometrial cancer is the most common gynecological tumor in developed countries, and its prevalence is increasing [1]. Although early-stage endometrial cancer generally has a favorable outcome with standard treatment involving surgical resection followed by adjuvant therapy, up to $30 \%$ of endometrial cancer patients are diagnosed with International Federation of Gynecology and Obstetrics (FIGO) stage III and IV disease, with extrapelvic metastasis or even distant metastasis [2]. Thus, it is necessary to identify a new chemical compound or drug that can be used for therapy.

Ellagic acid (EA) is a fused four ring compound that is widely found in fruits and other foods, such as berries, grapes, green tea, nuts, pomegranates and Alchemilla vulgaris L. extract [3]. Previous studies have shown that EA possesses strong antioxidant [4], anti-inflammatory [5] and anticarcinogenic properties [6]. Moreover, through in vitro experiments and animal model studies, EA was shown to have a potent suppressive effect on a variety of carcinogen-induced tumors [7-9]. However, there are still few studies regarding the effects of EA on endometrial cancer, and the mechanisms by which EA exerts its anticancer effect remain unknown.

In recent years, the explosive growth of bioinformatics has offered a better method for predicting drug-target genes or proteins using multiplatform analysis. In this study, four public web-based databases were used, DrugBank [10], STRING [11], WebGestalt [12] and cBioPortal [13], to identify the targets of EA. For more precise data-mining, the targets were screened step by step, and the final core targets were PIK3CA and PIK3R1. 
To verify the predictive result, a series of experiments were carried out. The proliferation of KLE and AN3CA endometrial cancer cells was suppressed by EA, and EA caused cell cycle arrest and induced apoptosis. Furthermore, the results demonstrated that EA could inhibit the invasion and migration of KLE and AN3CA cells by inhibiting the PI3K signaling pathway. In vivo lung metastasis in BALB/c nude mice was also inhibited by EA, based on the SUVmax value of PET scans and tissue hematoxylin and eosin (HE) staining. All these data show that EA exerts antitumor effects in endometrial cancer and can suppress cell invasion and migration by targeting the PI3K signaling pathway both in vitro and in vivo. This study presents a new approach to predict drug targets and indicates that EA might be a new therapeutic compound to target PI3K in endometrial cancer.

\section{Materials and Methods}

\section{Identification of drug target proteins}

The DrugBank database (https://www .drugbank.ca/) is a unique bioinformatics and cheminformatics resource that combines detailed drug data with comprehensive drug target (i.e., sequence, structure, and pathway) information [10]. The database has been widely used to facilitate drug and in silico drug target discovery and contains 8261 drug entries, including 2021 FDA-approved small molecule drugs, 233 FDA-approved biotech (protein/peptide) drugs, 94 nutraceuticals and over 6000 experimental drugs. DrugBank was used to find the interaction between EA and its target proteins and to construct the first level network. The target proteins were further sent to STRING to generate the second level network.

\section{Generation of the second level network using STRING}

STRING (http://www.string-db.org/ Version: $10.0)$ is an open-source database for protein-protein interaction networks [11]. It provides a critical assessment and integration of protein-protein interactions, including direct and indirect associations. The latest version covers more than 2000 organisms, 9.6 million proteins and 184 million interactions. The EA target proteins were input into STRING to generate a protein-protein interaction network.

\section{Pathway enrichment analysis and hub gene confirmation}

The genes of the first and the second level networks were analyzed using WebGestalt (http://www.webgestalt.org/) [12]. Although no pathway was shown to be specifically and directly associated with cancer, four pathways (ErbB signaling pathway, HIF-1 signaling pathway, Ras signaling pathway and PI3K-Akt signaling pathway) were generally related to many cancer types, and nine genes in the four pathways overlapped and seemed to be potential hub genes.

\section{Genetic alteration data from cBioPortal}

The Cancer Genome Atlas (TCGA) aims to find the key genomic changes in DNA that cause tumors in 33 types of cancer. cBioPortal (http://www .cbioportal.org/) [13] is a visualized open platform for exploring multidimensional genomics data based on TCGA. In this study, cBioPortal was used to explore the nine potential hub genes in endometrial cancer studies to find the most genetically altered genes.

\section{Reagents and antibodies}

Ellagic acid was purchased from Sigma-Aldrich (St. Louis, MO, USA). Cell Counting Kit 8 (CCK8) was purchased from Kunmamoto (Japan). Antibodies targeting PI3 kinase p85 (\#4292, 1:1000), phospho-PI3 kinase p85 (Tyr458)/p55 (Tyr199) (\#4228, 1:1000), MMP9 (\#13667, 1:1000), and GAPDH (\#5174, 1:1000) were purchased from Cell Signaling Technology, Beverly, MA, USA.

\section{Cell lines and culture conditions}

The KLE and AN3CA endometrial carcinoma cell lines were obtained from Shanghai Institute for Biological Sciences, Chinese Academy of Sciences. All cell lines were cultured in DMEM/F12 (Gibco, Invitrogen) supplemented with 10\% FBS (Invitrogen) and $1 \%$ antibiotics at $37{ }^{\circ} \mathrm{C}$ in a $5 \% \mathrm{CO}_{2}$ incubator.

\section{Cell migration and invasion assay}

Cells $\left(3 \times 10^{4}\right)$ were suspended in $200 \mu \mathrm{L}$ of medium without fetal bovine serum and seeded in the upper compartment of the chamber. Then, $600 \mu \mathrm{L}$ of medium containing $10 \%$ fetal bovine serum was added to the lower compartment. In addition, $20 \mu \mathrm{M}$ EA or control was added to the upper and lower compartments. The cells were incubated at $37^{\circ} \mathrm{C}$ with $5 \% \mathrm{CO}_{2}$ for $24 \mathrm{~h}$, and those that migrated through the membrane were fixed in methanol and stained with hematoxylin-eosin. Cells in five randomly selected fields were counted using a Leica DMI300B microscope (Leica, Wetzlar, Germany) at 200x magnification. The data are presented as the mean \pm SD based on three independent experiments.

Invasion assays were performed with $8-\mu \mathrm{m}$ pore size polycarbonate inserts coated with Matrigel (BD Biosciences, San Jose, CA, USA) and incubated at 37 ${ }^{\circ} \mathrm{C}$ for $4 \mathrm{~h}$. The assay steps were the same as those for the cell migration assay described above. 


\section{Cell proliferation assay}

Cells were counted and seeded into 96-well plates at a density of 5,000 cells per well. After $24 \mathrm{~h}$, the cells were treated with the control (DMSO 0.1\%) or $20 \mu \mathrm{M}$ EA. At $0 \mathrm{~h}, 24 \mathrm{~h}, 48 \mathrm{~h}$, and $72 \mathrm{~h}$ following treatment, cell proliferation was measured using a CCK8 assay, and the results were measured at a wavelength of $450 \mathrm{~nm}$. The experiment was repeated three times independently.

\section{Fluorescence-activated cell sorting (FACS)}

For cell cycle analysis, cells were seeded at $2 \times 10^{5}$ per well in a six-well plate overnight and then cultured with $20 \mu \mathrm{M}$ EA for $24 \mathrm{~h}$. Cells were then trypsinized, rinsed with cold PBS, and fixed with 70\% ethanol at $4{ }^{\circ} \mathrm{C}$ overnight. The cells were treated with RNaseA at $37{ }^{\circ} \mathrm{C}$ for 30 minutes, stained with propidium iodide using a cell cycle detection kit (KeyGen Biotech, Nanjing, China) according to the manufacturer's instructions and then analyzed using a FACSCalibur flow cytometer (BD Biosciences) and BD Cell Quest software. For apoptosis analysis, after the cells were seeded, $20 \mu \mathrm{M}$ EA was added and cultured with the cells for $48 \mathrm{~h}$. Apoptosis was detected with Annex V-APC and propidium iodide (Annexin V-APC Apoptosis Detection Kit, KeyGEN) following the manufacturer's instructions. Samples were analyzed using an LSRFortessa system (BD Biosciences).

\section{Real-time PCR}

Total RNA was extracted from cells using TRIzol reagent (Invitrogen). cDNA was generated using PrimeScriptTM RT reagent (Takara, Dalian, China). Real-time PCR was performed in a $25-\mu \mathrm{L}$ reaction containing $2 \mu \mathrm{L}$ of cDNA using a Light Cycler $480 \mathrm{II}$ Real-Time PCR system (Roche Diagnostics, Basel, Switzerland). ACTB was used as the endogenous control. For PCR data analysis, the threshold cycle $(\mathrm{Ct})$ values of each sample were analyzed using the $2^{-\Delta \Delta C t}$ method. Each experiment was performed in triplicate. The PCR primer sequences were PI3KCA, (forward) CCACGACCATCATCAGGTGAA and (reverse) CCTCACGGAGGCATTCTAAAGT and PIK3R1, (forward) ACCACTACCGGAATGAAT CTCT and (reverse) GGGATGTGCGGGTATATT CTTC.

\section{Western blotting analysis}

Total cell lysates were obtained using a Protein Extraction Kit (KeyGene Biotech, Nanjing, China) and quantified using a BCA Protein Assay Kit (Thermo Fisher, USA). Proteins were separated by SDS-PAGE and transferred to PVDF membranes (Millipore). The membranes were blocked with blocking buffer (PBS,
LI-COR, USA) and then incubated with primary antibodies for one hour, followed by incubation with horseradish peroxidase-conjugated secondary antibodies. Blots were visualized via chemiluminescence (Thermo Fisher) and analyzed with a MicroChemi 4.2 imaging system (DNR Bio-Imaging Systems, Israel). Western blotting analyses were repeated at least three times.

\section{Animal experiments}

Briefly, $2 \times 10^{6}$ endometrial carcinoma cells (KLE and $\mathrm{AN} 3 \mathrm{CA}$ ) in $100 \mu \mathrm{L}$ of normal saline were injected into the tail vein of five-week-old female BALB/c nude mice that had previously been divided into four groups ( $\mathrm{n}=5$ for each group). After two weeks, each group injected with KLE or AN3CA cells was treated with either control solution or $20 \mu \mathrm{M}$ EA via daily intraperitoneal injection for 3 weeks. At the sixth week after cell injection, 18-fluorodeoxyglucose positron emission tomography (18F-FDG PET) scans were performed using a PET scanner (Metis 1800, Madic Technology Co., Ltd.). For semiquantitative analysis, the maximum standardized uptake value (SUVmax) was measured and calculated.

After the PET scan, whole lung tissues were isolated from the mice, and tissue sections were stained with hematoxylin and eosin (HE). The metastatic cancer nests were observed at $10 \times 10$ magnification using an inverted microscope (Leica DMI300B). For all animal experiments, all procedures were performed in accordance with the Guide for the Care and Use of Laboratory Animals and the institutional ethical guidelines for animal experiments. Permission for the experiments was received from the Shengjing Hospital of China Medical University Animal Care and Use Committee.

\section{Statistical analysis}

All data are presented as the mean \pm SD of three independent experiments. Statistical analyses were conducted using SPSS 22.0 (IBM, NY, USA) and Prism 5 (GraphPad Software, San Diego, USA) software. Comparisons between two groups were analyzed using Student's t-test, and $\mathrm{p}$ values $<0.05$ were considered statistically significant.

\section{Results}

\section{Identification of EA target proteins}

To identify the direct target proteins of EA, ellagic acid was queried in the DrugBank as the input. The results showed that the therapeutic action of ellagic acid primarily involves antioxidant, antiproliferative and anticancer effects, but the exact mechanism was still being investigated. Figure 1A presents a diagram showing that EA is an inhibitor of 
17 different proteins, and the detailed information is shown in Table 1. Next, protein-protein interactions were explored using the STRING database, and the 17 proteins that were potential primary targets of EA (the first level) were queried in the STRING database to obtain a network of protein-protein interactions. In total, 110 proteins were exported, but some had no interaction with the other proteins. The final interaction network after the proteins without interactions were removed is shown in Figure 1B.

Table 1. The direct target of ellagic acid from Drugbank database

\begin{tabular}{|c|c|c|c|}
\hline Target & Gene Name & Actions & UniProt ID \\
\hline Carbonic anhydrase 1 & CA1 & inhibitor & P00915 \\
\hline Carbonic anhydrase 2 & CA2 & inhibitor & P00918 \\
\hline Carbonic anhydrase 3 & CA3 & inhibitor & P07451 \\
\hline Carbonic anhydrase 4 & CA4 & inhibitor & P22748 \\
\hline Carbonic anhydrase $5 \mathrm{~A}$ & CA5A & inhibitor & P35218 \\
\hline Carbonic anhydrase 5B & CA5B & inhibitor & Q9Y2D0 \\
\hline Carbonic anhydrase 6 & CA6 & inhibitor & P23280 \\
\hline Carbonic anhydrase 7 & CA7 & inhibitor & P43166 \\
\hline Carbonic anhydrase 9 & CA9 & inhibitor & Q16790 \\
\hline Carbonic anhydrase 12 & CA12 & inhibitor & O43570 \\
\hline Carbonic anhydrase 14 & CA14 & inhibitor & Q9ULX7 \\
\hline $\begin{array}{l}\text { Casein kinase II subunit } \\
\text { alpha }\end{array}$ & CSNK2A1 & inhibitor & P68400 \\
\hline $\begin{array}{l}\text { cAMP-dependent protein } \\
\text { kinase catalytic subunit } \\
\text { alpha }\end{array}$ & PRKACA & $\begin{array}{l}\text { inhibitor, } \\
\text { competitive }\end{array}$ & P17612 \\
\hline Protein kinase $\mathrm{C}$ alpha type & PRKCA & $\begin{array}{l}\text { inhibitor, } \\
\text { competitive }\end{array}$ & P17252 \\
\hline Protein kinase $C$ beta type & PRKCB & $\begin{array}{l}\text { inhibitor, } \\
\text { competitive }\end{array}$ & P05771 \\
\hline Tyrosine-protein kinase SYK & SYK & inhibitor & P43405 \\
\hline Squalene monooxygenase & SQLE & inhibitor & Q14534 \\
\hline
\end{tabular}

\section{KEGG pathway enrichment analysis using WebGestalt}

KEGG pathway enrichment analysis was carried out to analyze the function of EA-mediated gene sets using WebGestalt. The proteins screened from STRING were analyzed. Ten KEGG pathways were enriched and are shown in Table 2. From the pathway analysis results, no specific disease pathway was shown, but four pathways should be focused on (ErbB signaling pathway, HIF-1 signaling pathway, Ras signaling pathway and PI3K-Akt signaling pathway) that were generally related to oncogenesis in many cancer types. The overlapped genes from the four pathways were found (Figure 2A), presenting nine genes considered to be the hub genes of the four pathways.

\section{Genetic alteration analysis in endometrial cancer using cBioPortal}

Next, the nine hub genes were analyzed with cBioPortal to explore gene mutations in endometrial cancer. The results showed that the nine genes accounted for a great proportion of the genetic alterations in endometrial cancer (Figure 2B), especially PIK3CA and PIK3R1 (for which the mutation rates were $41 \%$ and $24 \%$, respectively), which seemed to be significantly related to the oncogenesis of endometrial cancer.
A

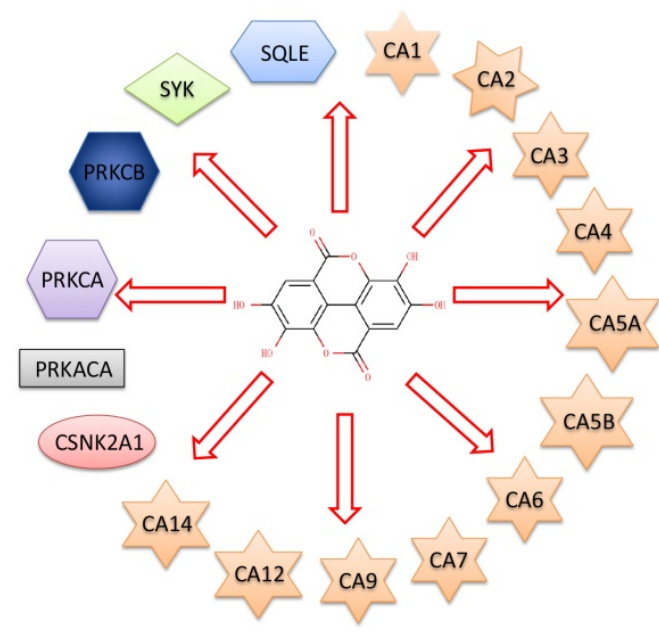

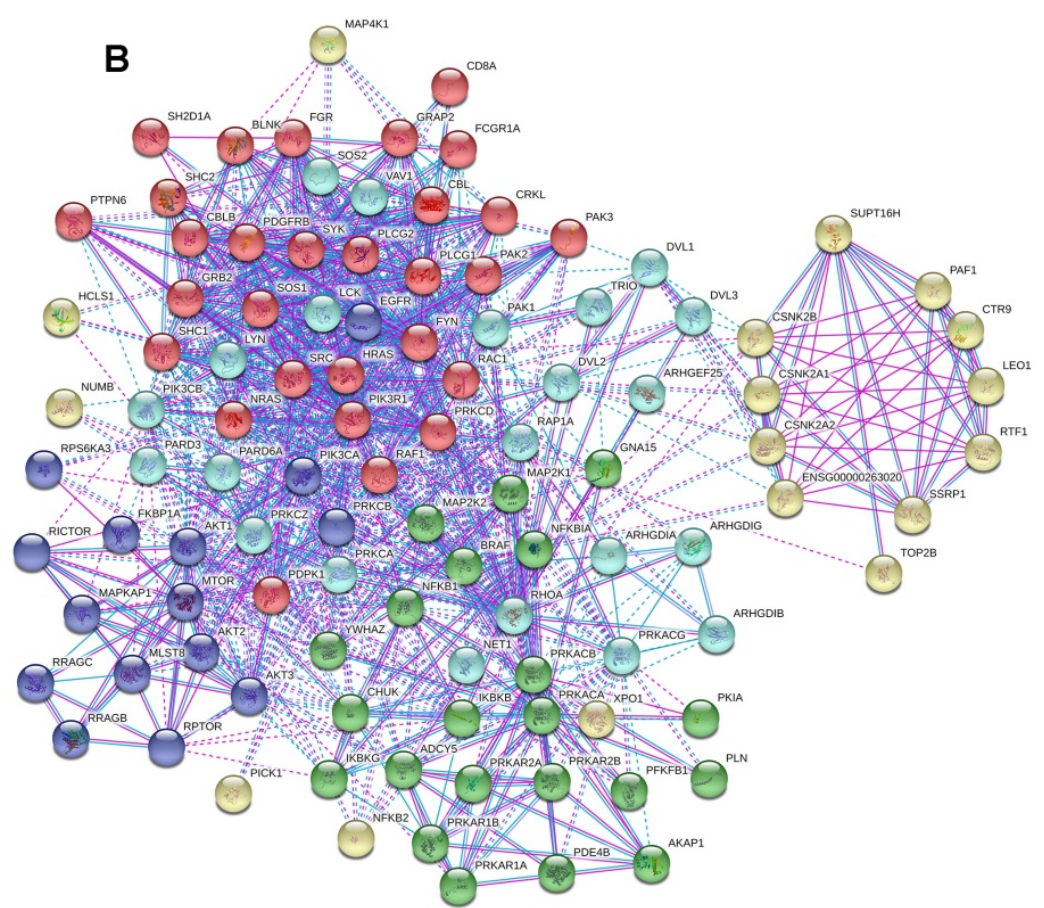

Figure 1. (A) Diagram of ellagic acid target proteins from the DrugBank database. (B) Network of the 17 EA-targeted proteins and their interactions from the STRING database (non-interacting proteins were removed). 
Table 2. KEGG pathway analysis in WebGestalt

\begin{tabular}{|c|c|c|c|}
\hline Pathway & No. of Gene & Entrez Gene & Statistics \\
\hline HIF-1 signaling pathway & 31 & $\begin{array}{l}102613871956206420724753091479052905291529352945295545835578557956045966198 \\
74227428\end{array}$ & $\begin{array}{l}\mathrm{C}=103 ; \mathrm{O}=21 ; \mathrm{E}=1.49 ; \mathrm{R}=14.09 ; \\
\mathrm{P} \text { Value }=0 \mathrm{e}+00 ;\end{array}$ \\
\hline $\begin{array}{l}\text { Chemokine signaling } \\
\text { pathway }\end{array}$ & 29 & $\begin{array}{l}104511147139920723236288532653874790479248935290529152935294529555665567 \\
556855795580560458796464665467374097410998\end{array}$ & $\begin{array}{l}\mathrm{C}=187 ; \mathrm{O}=29 ; \mathrm{E}=2.71 ; \mathrm{R}=10.72 ; \\
\mathrm{P} \text { Value }=0 \mathrm{e}+00\end{array}$ \\
\hline $\begin{array}{l}\text { EGFR tyrosine kinase } \\
\text { inhibitor resistance }\end{array}$ & 23 & $\begin{array}{l}1956206420724752885326548935290529152935294529555785579560457285815966198 \\
646466546737422\end{array}$ & $\begin{array}{l}\mathrm{C}=81 ; \mathrm{O}=23 ; \mathrm{E}=1.17 ; \mathrm{R}=19.62 ; \mathrm{P} \\
\text { Value=0e+00; }\end{array}$ \\
\hline Endocrine resistance & 27 & $\begin{array}{l}109111114195623532475277828853265372552905294529555665567559455955599572 \\
58945955966198646467146737157\end{array}$ & $\begin{array}{l}\mathrm{C}=98 ; \mathrm{O}=27 ; \mathrm{E}=1.42 ; \mathrm{R}=19.04 ; \mathrm{P} \\
\text { Value }=0 \mathrm{e}+00\end{array}$ \\
\hline ErbB signaling pathway & 25 & $\begin{array}{l}102613991956206420724752885326546094690489350625290529152935294529555785579 \\
5604619864646654673867\end{array}$ & $\begin{array}{l}\mathrm{C}=88 ; \mathrm{O}=25 ; \mathrm{E}=1.27 ; \mathrm{R}=19.63 ; \mathrm{P} \\
\text { Value=0e+00; }\end{array}$ \\
\hline Focal adhesion & 28 & $\begin{array}{l}104511399195620642072885326538746595062529052915293529452955578557956045728 \\
587959664646654673740974107422998\end{array}$ & $\begin{array}{l}\mathrm{C}=203 ; \mathrm{O}=28 ; \mathrm{E}=2.94 ; \mathrm{R}=9.53 ; \mathrm{P} \\
\text { Value=0e+00; }\end{array}$ \\
\hline $\begin{array}{l}\text { Phospholipase D signaling } \\
\text { pathway }\end{array}$ & 24 & $\begin{array}{l}195620722072280823236247528853265387489352905291529352945295533753385578 \\
560462376464665468509846\end{array}$ & $\begin{array}{l}\mathrm{C}=144 ; \mathrm{O}=24 ; \mathrm{E}=2.08 ; \mathrm{R}=11.52 ; \\
\mathrm{P} \text { Value }=0 \mathrm{e}+00 ;\end{array}$ \\
\hline PI3K-Akt signaling pathway & 46 & $\begin{array}{l}101710261147195620724752885326536674193460947904893529052915293529452955578 \\
5585558656045728587959661986654685071577422930\end{array}$ & $\begin{array}{l}\mathrm{C}=341 ; \mathrm{O}=31 ; \mathrm{E}=4.93 ; \mathrm{R}=6.28 ; \mathrm{P} \\
\text { Value }=0 \mathrm{e}+00 ;\end{array}$ \\
\hline $\begin{array}{l}\text { Sphingolipid signaling } \\
\text { pathway }\end{array}$ & 23 & $\begin{array}{l}20722072323632653874790489352905291529352945295533753385578557956045728581 \\
587959671579846\end{array}$ & $\begin{array}{l}\mathrm{C}=120 ; \mathrm{O}=23 ; \mathrm{E}=1.74 ; \mathrm{R}=13.24 ; \\
\mathrm{P} \text { Value }=0 \mathrm{e}+00 ;\end{array}$ \\
\hline Ras signaling pathway & 32 & $\begin{array}{l}114719562072280827040288532653874790489350625290529152935294529553375338 \\
5566556755685578557956045879623764646654742275359846998\end{array}$ & $\begin{array}{l}\mathrm{C}=229 ; \mathrm{O}=32 ; \mathrm{E}=3.31 ; \mathrm{R}=9.66 ; \mathrm{P} \\
\text { Value }=0 \mathrm{e}+00 ;\end{array}$ \\
\hline
\end{tabular}

The row lists the following statistics: C: the number of reference genes in the category; O: the number of genes in the gene set and also in the category; E: the expected number in the category; R: ratio of enrichment; pValue: p-value from hypergeometric test.

A

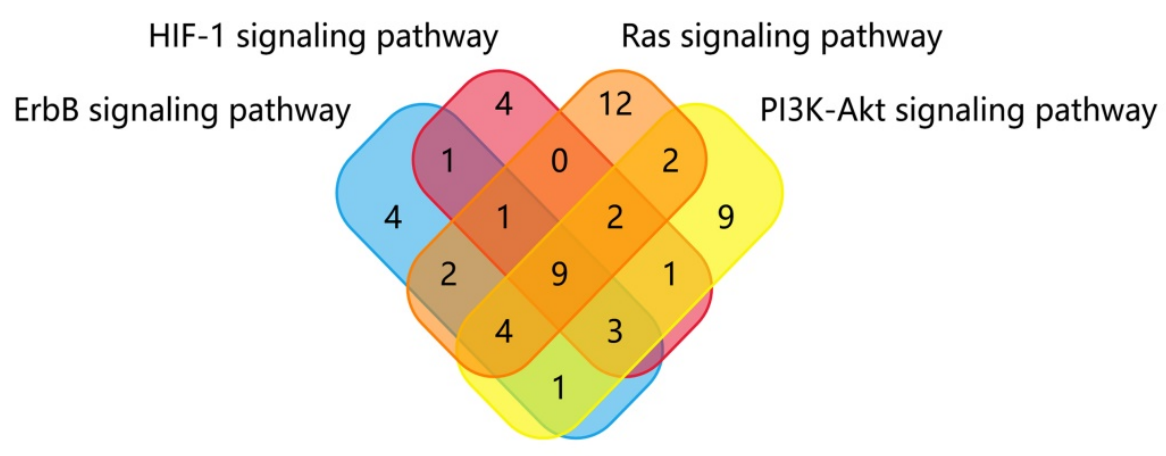

B

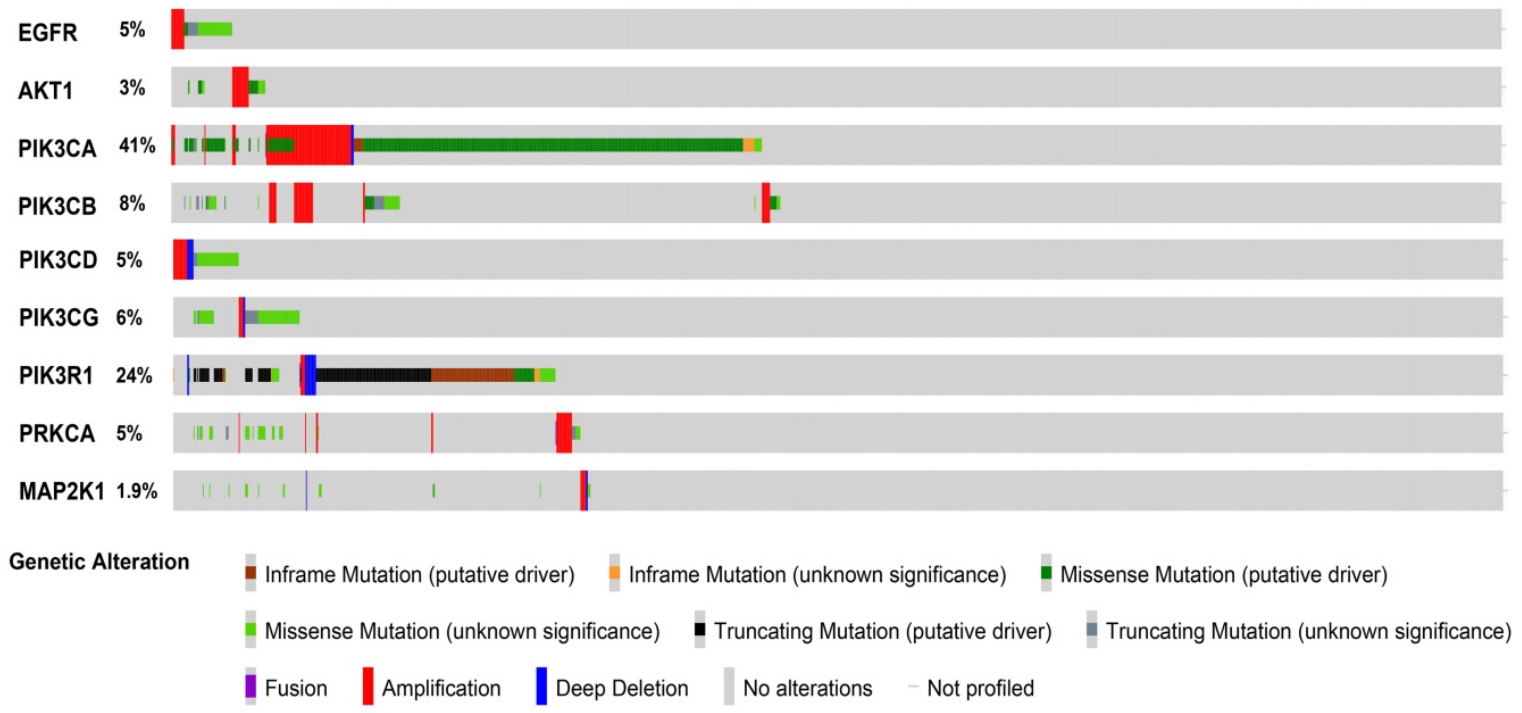

Figure 2. (A) Overlapping of genes in the four pathways that were enriched in the WebGestalt database. (B) Genetic alterations of nine potential hub genes in endometrial carcinoma.

\section{EA inhibits the migration and invasion of KLE and AN3CA cells}

The IC50 values of EA for KLE and AN3CA cells (shown in Figure S1) were $18.13 \mu \mathrm{M}$ and $19.05 \mu \mathrm{M}$, respectively, and thus, $20 \mu \mathrm{M}$ was used as the experimental concentration. Transwell assays were used to evaluate the effect of EA on the migration and invasion of KLE and AN3CA cells. The migration assay showed that $20 \mu \mathrm{M}$ EA significantly inhibited cell migration ability compared with control group 
cells (Figure 3). Furthermore, invasion assays showed that $20 \mu \mathrm{M}$ EA decreased the number of invasive cells by over $50 \%$ compared with the control group (Figure $3)$.

\section{EA suppresses the proliferation of KLE and AN3CA cells by inducing cell cycle arrest and apoptosis}

To explore the effect of EA on endometrial cancer cell growth, a CCK8 assay was used to examine cell proliferation. KLE and AN3CA endometrial cancer cells were treated with or without $20 \mu \mathrm{M}$ EA for $0 \mathrm{~h}, 24 \mathrm{~h}, 48 \mathrm{~h}$ and $72 \mathrm{~h}$. EA exerted an antitumor effect on both KLE and AN3CA cells at $24 \mathrm{~h}$, but the effect was not significant. However, EA strongly inhibited proliferation at $48 \mathrm{~h}$ and $72 \mathrm{~h}$, and the inhibition rate was nearly 50\%. All these data demonstrate that EA inhibited the proliferation of endometrial cancer cells in a time-dependent manner (Figure 4A).

Cell cycle and apoptosis were examined to further elucidate the mechanism by which EA inhibits the proliferation of endometrial cancer cells. As shown in Figure 4B, $20 \mu \mathrm{M}$ EA caused cell cycle arrest at G1 phase in both KLE and AN3CA cells, and the number of cells in $S$ phase was decreased accordingly. Similarly, EA induced endometrial cancer cell apoptosis, and the rate of apoptosis was increased to $25 \%$ and $40 \%$ in KLE and AN3CA cells, respectively (Figure 5A). All these findings indicate that EA can inhibit the proliferation of endometrial cancer cells by inducing cell cycle arrest and apoptosis.

\section{EA inhibits MMP9 expression via downregulation of the PI3K signaling pathway}

To explore the molecular mechanism of migration and invasion, real-time PCR and western blotting were conducted. According to the findings from cBioPortal (Figure 2B), PIK3CA and PIK3R1 were the most genetically altered genes, and thus, real-time PCR was used to examine expression changes in PIK3CA and PIK3R1 after EA treatment. PIK3CA and PIK3R1 were prominently decreased in the $20 \mu \mathrm{M}$ EA group compared with the control group (Figure 5B). Next, western blotting was used to detect the signaling pathway with which EA perhaps interacted. EA did not decrease total PI3K expression but inhibited the phosphorylation PI3K (p-PI3K), which eventually caused downregulation of MMP9 (Figure 5C). All these data were in accordance with the results of the migration and invasion assays and demonstrated that EA might exert its antitumor function by regulating the PI3K signaling pathway.
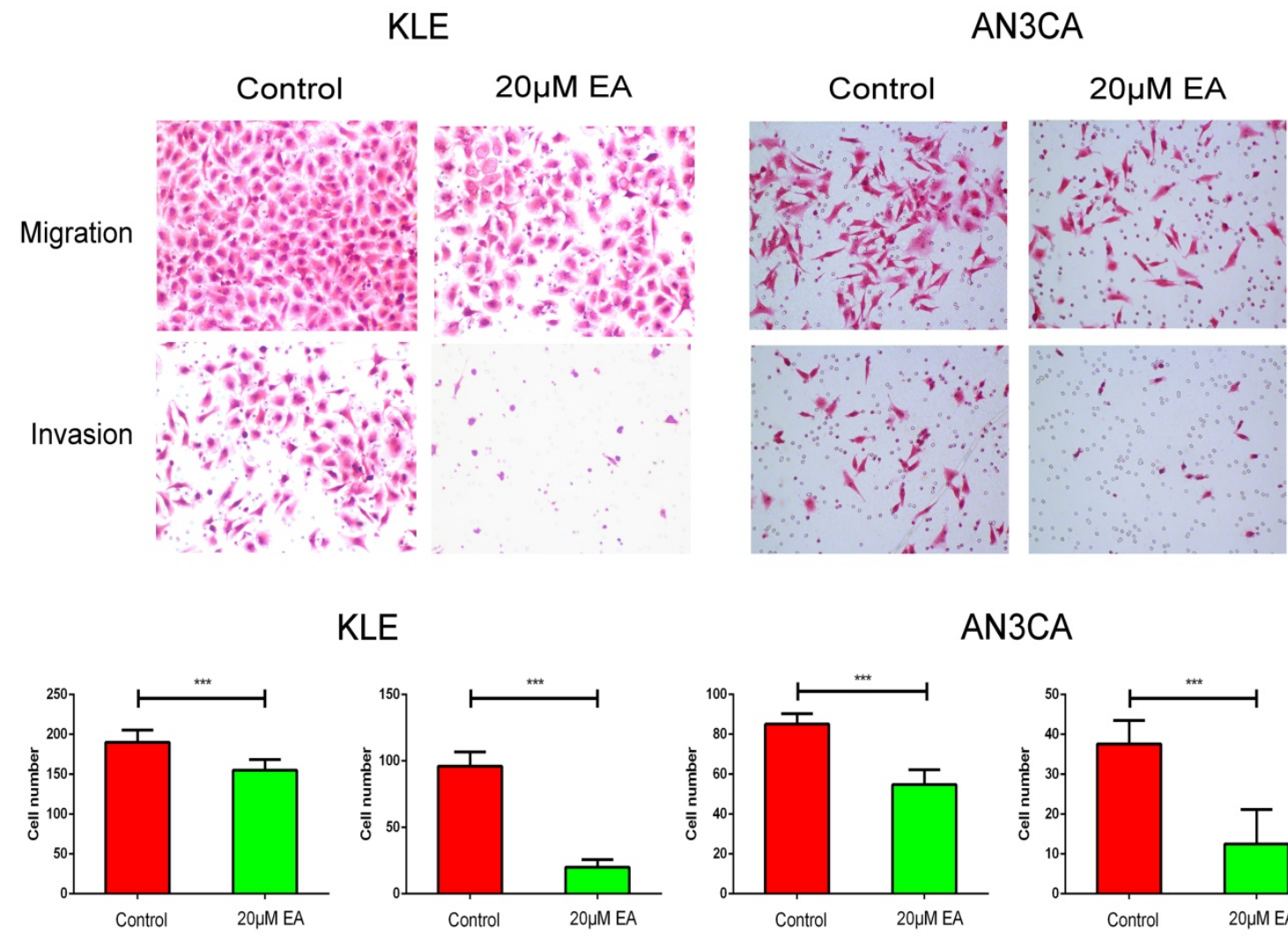

KLE

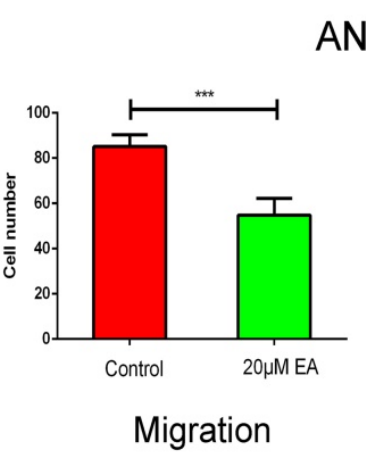

AN3CA

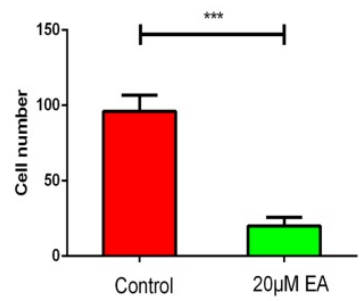

Invasion

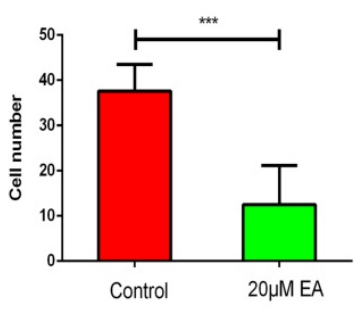

Invasion

Figure 3. Migration and invasion assays of KLE and AN3CA cells treated with the control or $20 \mu \mathrm{M}$ EA. All the cells in five separate fields were counted under a microscope. Original magnification $\times 200$. The data are shown as the means \pm SD of three independent experiments. $* * * p<0.001$ 
A

KLE

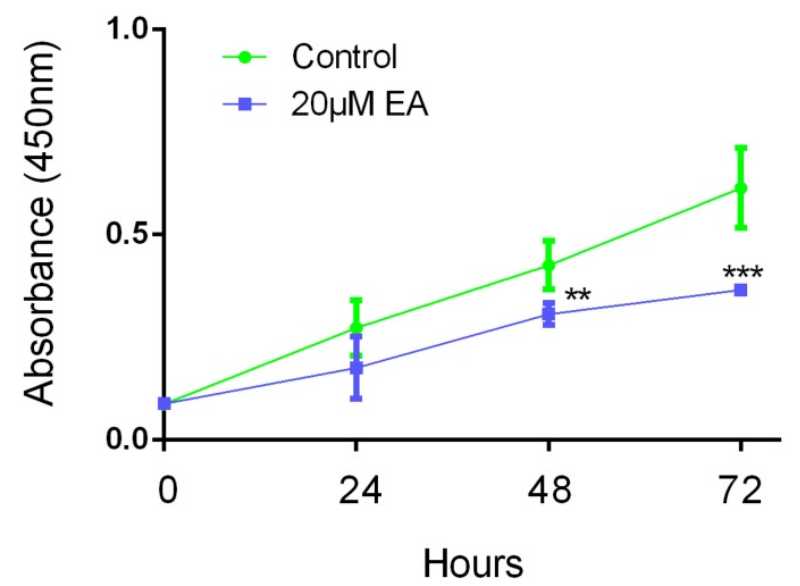

B
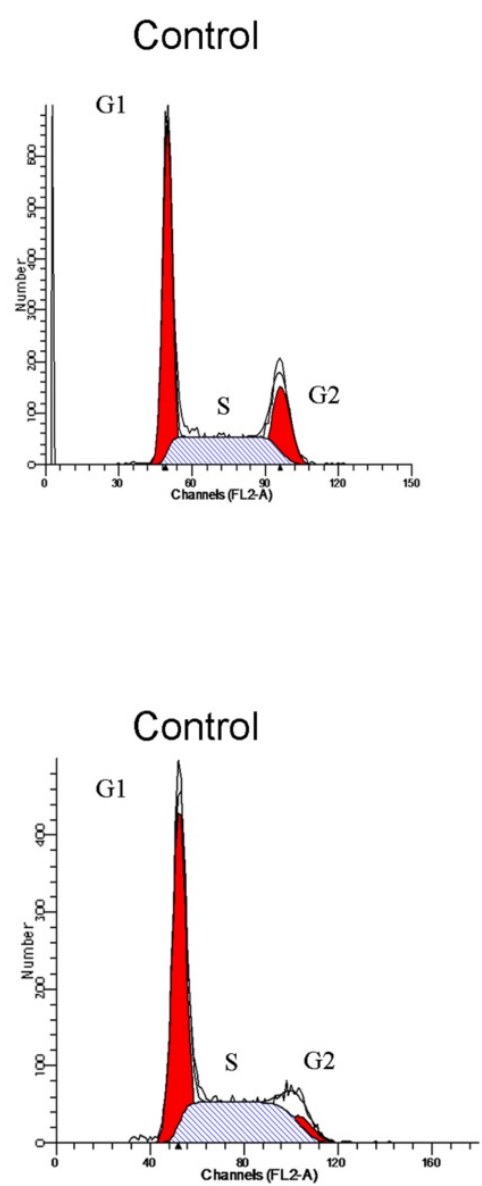

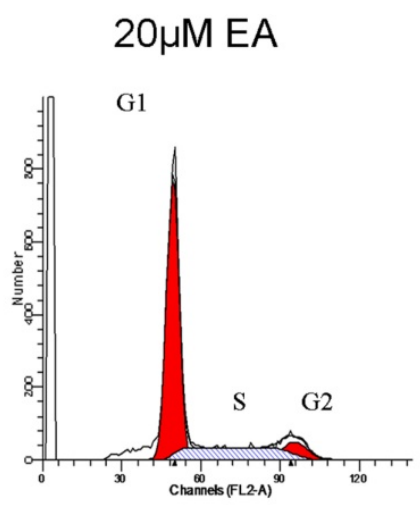

AN3CA
AN3CA

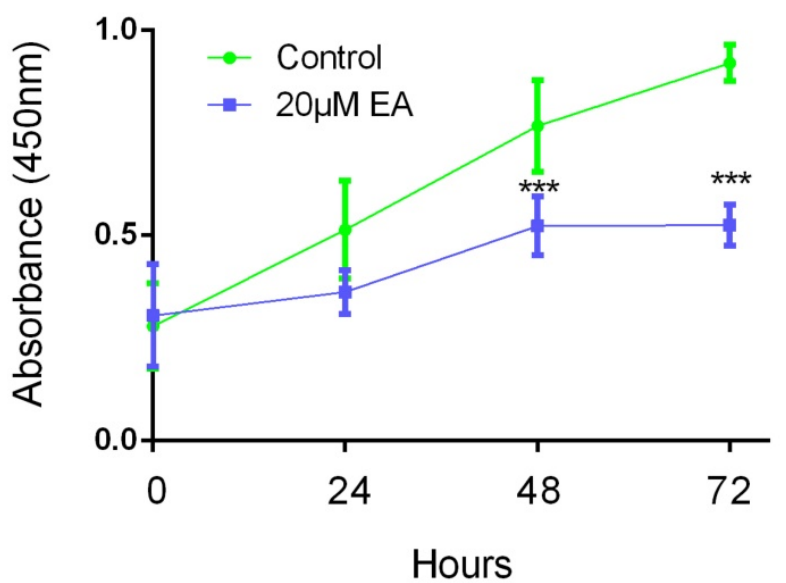

\section{KLE}
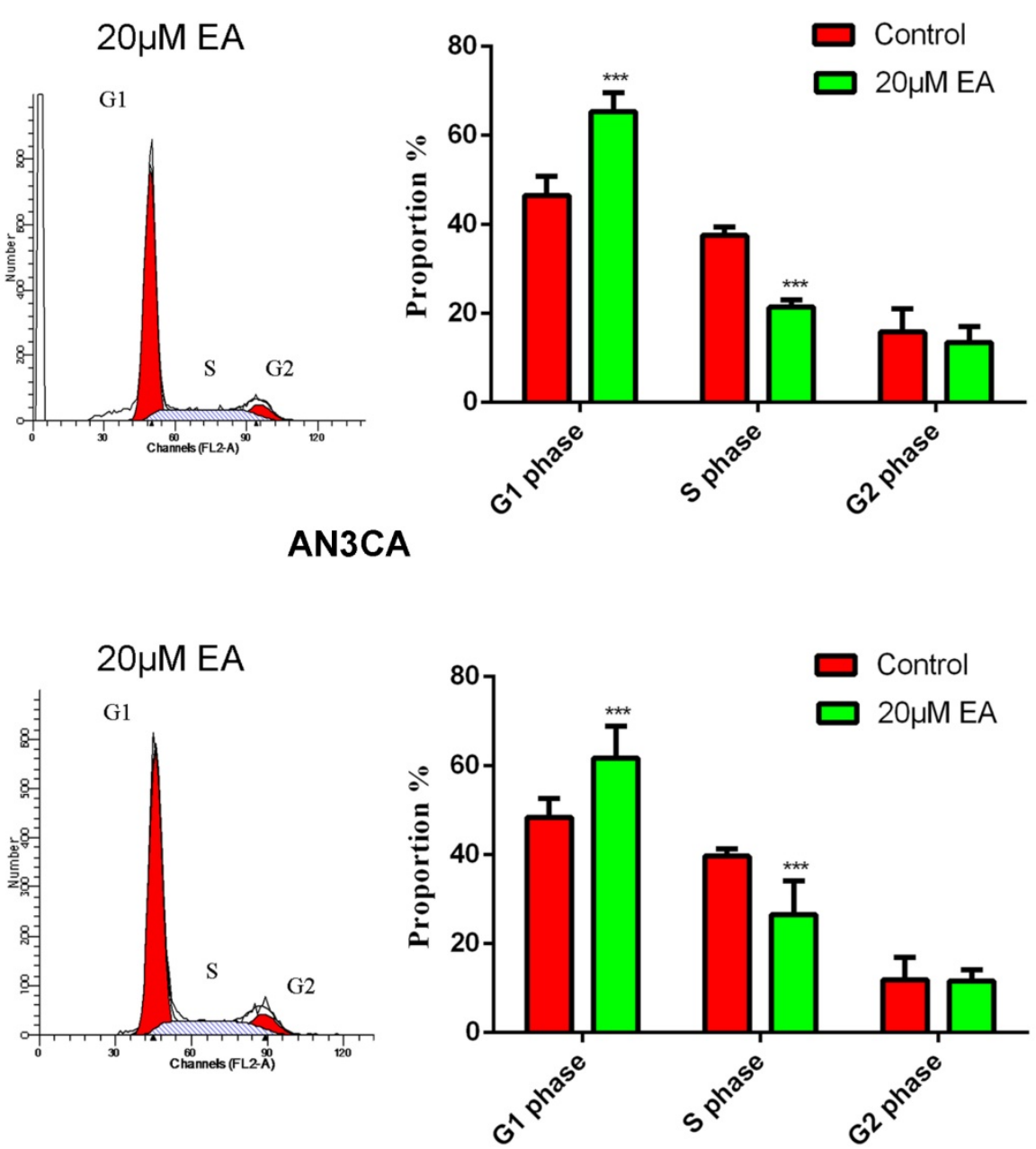

Figure 4. (A) EA inhibits the proliferation of KLE and AN3CA cells in a time-dependent manner. ${ }^{*}$ p $<0.01 ; * * * p<0.001$. (B) EA induces cell cycle arrest in G1 phase in endometrial cancer cells. ${ }^{* * *} \mathrm{p}<0.001$. 
A
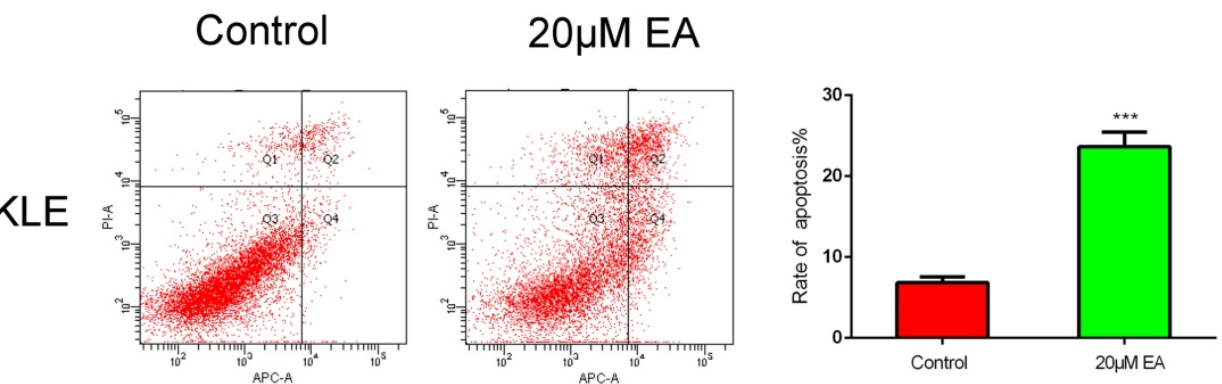

AN3CA
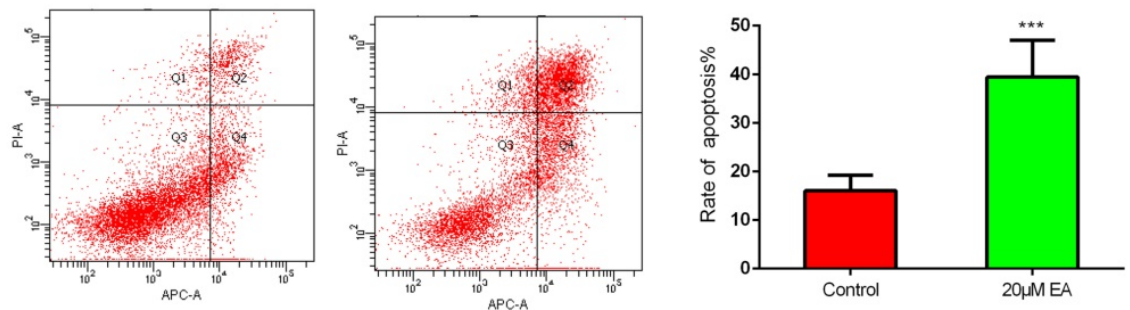

B

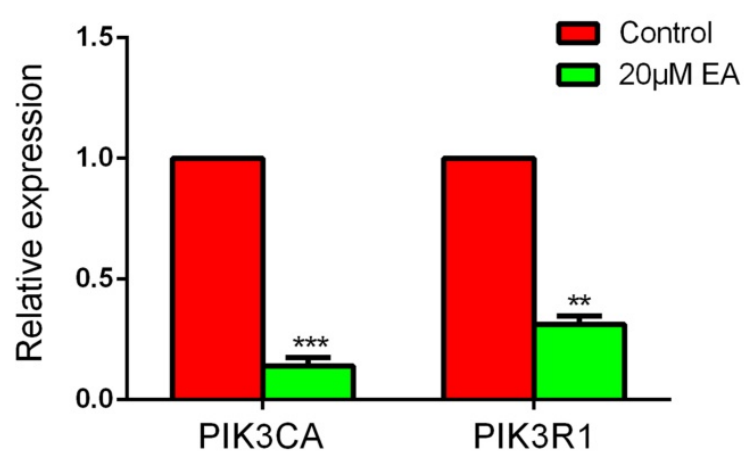

C

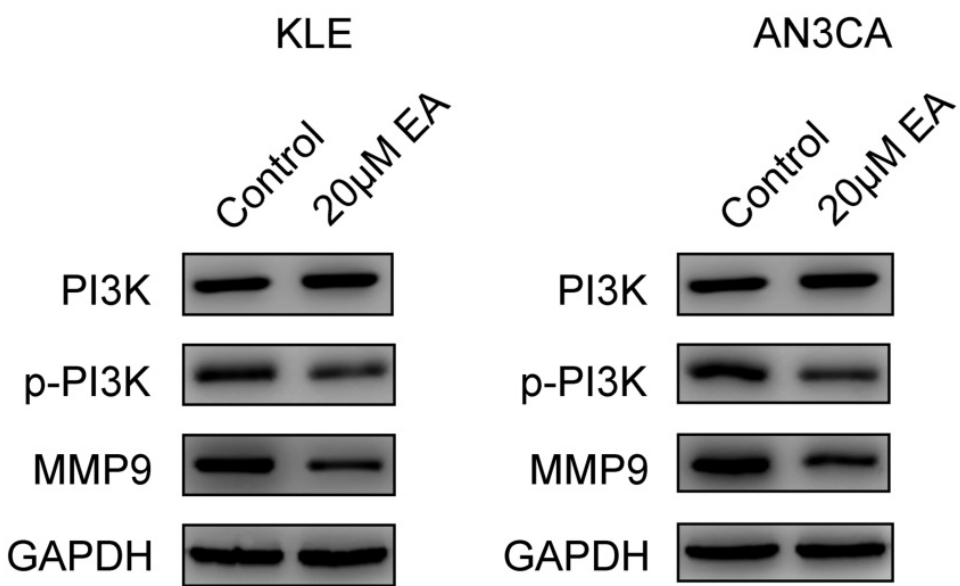

Figure 5. (A) EA increases apoptosis of KLE and AN3CA cells to $25 \%$ and $40 \%$, respectively. $* * *$ p $<0.001$. (B) Real-time PCR verified that EA decreased the expression of PI3KCA and PIK3R1. The data are shown as the means \pm SD. ${ }^{*} \mathrm{p}<0.01$; *** $\mathrm{p}<0.001$. (C) Western blotting analysis of PI3K, $\mathrm{p}-\mathrm{PI} 3 \mathrm{~K}$ and MMP9 expression in KLE and AN3CA cells treated with or without EA.

\section{EA suppresses distant metastasis in BALB/c nude mice}

To further investigate EA antimetastasis activity in vivo, KLE and AN3CA cells were intravenously injected into nude mice via the tail vein. Two weeks after injection, $20 \mu \mathrm{M} \quad \mathrm{EA}$ was injected intraperitoneally once per day for three weeks. A PET scan was performed on each mouse six weeks after the initial endometrial cancer cell injection. The mice in the $20 \mu \mathrm{M}$ EA treatment group showed significantly lower SUVmax values in the lungs than did mice in the control group (Figure 6A). The number of metastatic lesions based on HE staining 
A

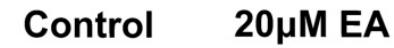
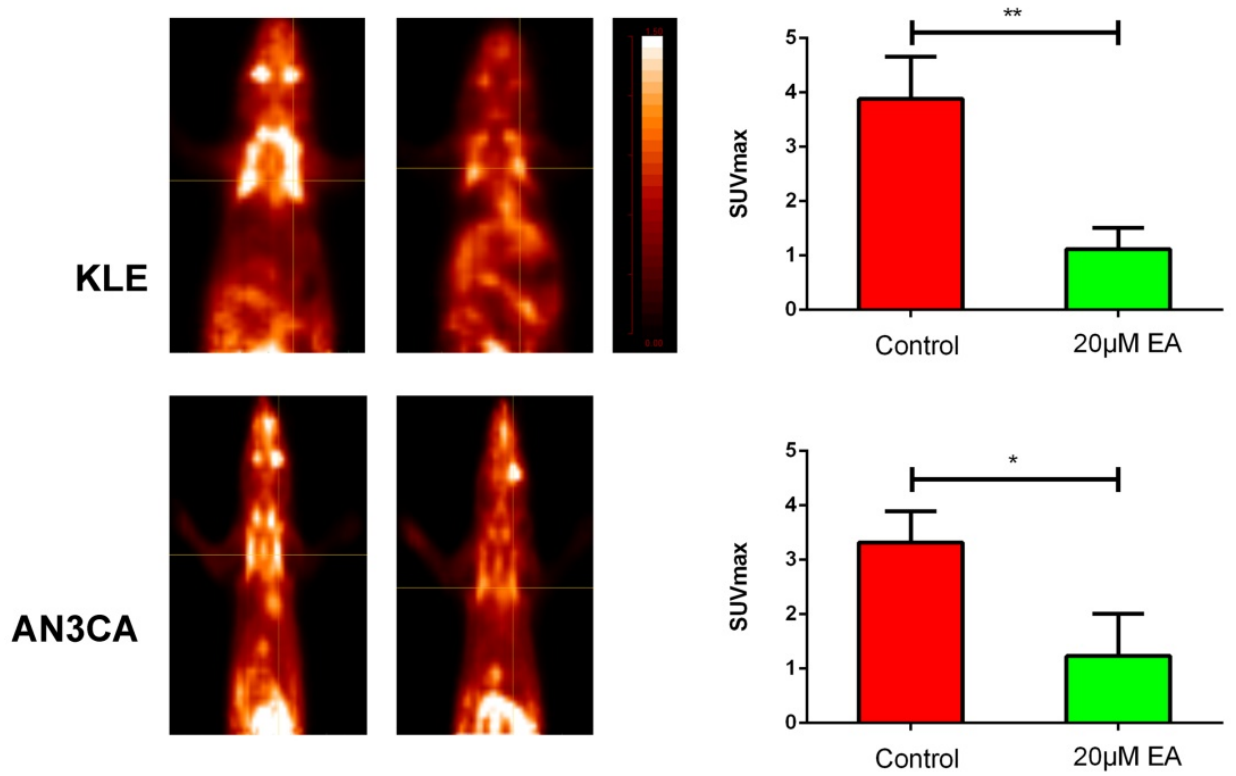

B

\section{KLE}

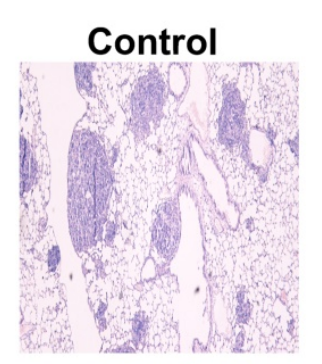

$20 \mu \mathrm{M}$ EA

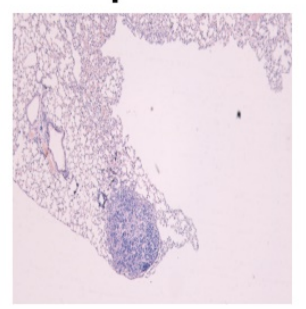

Control

AN3CA
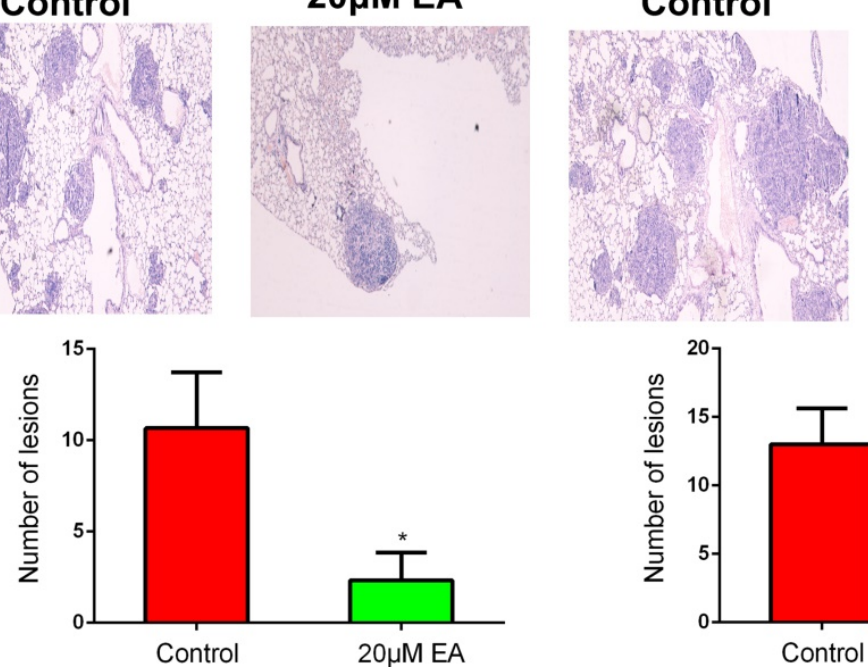

$20 \mu \mathrm{M}$ EA
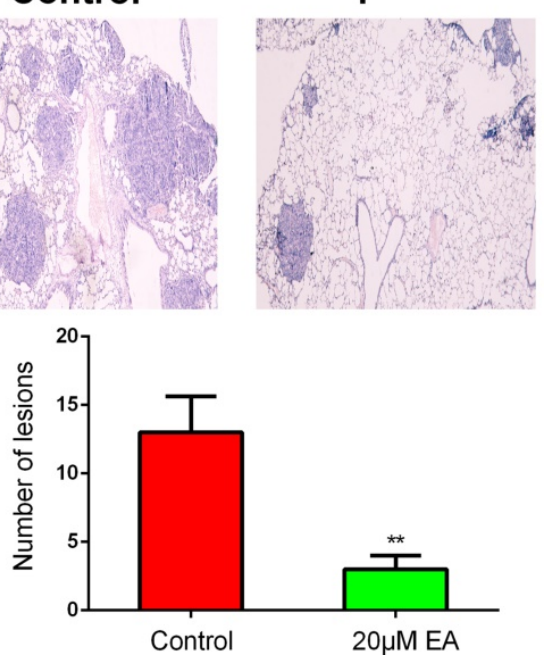

Figure 6. (A) PET scan showing that the SUVmax value was lower in the EA-treated group than in the control group. (B) Metastatic lesions in BALB/c nude mouse lungs stained by $\mathrm{HE}$ and the associated statistical data. The data are shown as the means $\pm \mathrm{SD}$. $*_{\mathrm{p}}<0.05 ; * * \mathrm{p}<0.01$.

supported the PET scan results, with fewer metastatic lesions observed in the lungs of BALB/c nude mice in the $20 \mu \mathrm{M}$ EA-treated group than in the lungs of mice in the control group (Figure 6B).

\section{Discussion}

During the last few decades, EA has been found to be possess antitumor activity and has been shown to inhibit tumor growth and metastasis by suppressing tumor cell proliferation, promoting apoptosis, and preventing angiogenesis and drug-resistance processes [14, 15]. The antitumor activity of EA was initially found in breast cancer; specifically, EA inhibited an important enzyme in the progression of breast cancer that converts androgens to estrogens [8]. Subsequently, EA was demonstrated to exert therapeutic effects against colon [16], prostate [17] and pancreatic cancer in vivo [18]. However, few studies have explored the function of EA in endometrial cancer, and the functional targets and molecular mechanism of EA in endometrial cancer are still unknown. With the development of bioinformatics, it is possible to predict the potential drug targets beforehand and verify them via experiments.

To determine the potential target proteins associated with EA's wide range of beneficial effects, our study employed a web-based bioinformatics 
analytical approach to connect EA with its targets. First, the direct protein targets of EA were identified using DrugBank. Second, a network of the interacting proteins among the first level proteins was obtained from the STRING database. Third, the entire network was analyzed by using WebGestalt to explore the enriched signaling pathways. Finally, overlapping targets from four tumor-related pathways were confirmed. To clarify the genetic alteration of these hub genes, the cBioPortal database was used to analyze the data, and the results revealed that EA might participate in the PI3K signaling pathway.

To explore the functions of EA in endometrial cancer, cellular function experiments were performed in our study. EA obviously inhibited KLE and AN3CA cell migration. Moreover, EA greatly suppressed the cell invasion ability. Wang et al demonstrated that EA could inhibit the migration and invasion ability of breast cancer cells in a dose-dependent manner [8]. In addition, Ceci et al found that EA reduced the invasiveness of bladder cancer cells by regulating VEGF-A [9]. To further examine the mechanism underlying the antimigration and anti-invasion ability of EA, real-time PCR was performed and confirmed that EA could decrease the expression of PIK3CA and PIK3R1 at the mRNA level. Moreover, western blotting was conducted to examine the expression of PI3K and MMP9. Although EA did not reduce total PI3K expression, EA definitely decreased the expression of p-PI3K, reducing activation of the downstream target MMP9. A similar result was also presented in a previous study[19], which showed that EA decreased the expression of $\mathrm{p}$-PI3K without down-regulating total PI3K in nonsmall cell lung cancer. In vivo, KLE and AN3CA cells were injected into BALB/c nude mice to simulate a metastatic environment. PET scans revealed that EA has an antimetastatic effect on endometrial cancer, and the SUVmax was much lower in the $20 \mu \mathrm{M}$ EA group than in the control group. The results of HE staining were also in agreement with those of the PET scans. All the results demonstrated that EA has the ability to depress cell migration and invasion ability both in vitro and in vivo.

Previous studies have mainly focused on the antiproliferation ability of EA in different types of cancer in vitro and in vivo $[8,9,18]$. The main reason for the antigrowth activity of EA is that it causes cell cycle arrest and induces apoptosis. In the present study, the IC50 values for EA in KLE and AN3CA cells were calculated, and then, CCK8 assays were used to examine the antiproliferation effect of EA at a concentration of $20 \mu \mathrm{M}$. The CCK8 assay data verified that KLE and AN3CA cells were suppressed by EA. Furthermore, cell cycle and apoptosis were evaluated via FACS. The results showed that EA could arrest cell cycle at G1 phase and induce apoptosis, which was in accordance with the results of the CCK8 assays. Liu et al found that EA caused cell cycle arrest at G1 phase and promoted apoptosis in nonsmall cell lung cancer by regulating the PI3K/Akt pathway [19]. In addition to direct inhibition of the PI3K signaling pathway, EA also improved the therapeutic efficacy of a PI3K inhibitor in breast cancer and improved the efficacy of PI3K-targeted cancer treatment [20]. In endometrial cancer, Abdelazeem et al showed that EA downregulated ROS formation and NHE1 expression, leading to decreased $\mathrm{Na}^{+} / \mathrm{H}^{+}$exchanger activity, $\mathrm{pHi}$, glucose uptake and lactate release in endometrial cancer cells, which presumably influenced the growth inhibition of endometrial cancer cells [21]. Based on the aforementioned results, EA can decrease the growth of endometrial cancer cells via multiple mechanisms.

The PI3Ks are a family of lipid kinases that are classified into three groups according to different structure and substrate preferences (Type I, II, and III) [22]. PIK3CA encodes the catalytic (p110) subunit of type I PI3Ks, which were first found by Volinia in 1994 using in situ hybridization [23]. PIK3CA is located on chromosome $3 \mathrm{q} 26.3$, is $34 \mathrm{~kb}$ long, and includes 20 exons. Mutations in PIK3CA lead to activation of the p110 subunit and stimulate mutation rates of PIK3CA vary in different cancer types, with $1 \% \sim 4 \%$ in nonsmall cell lung cancer [24, 25], $26 \%$ in breast cancer [26], 32\% in colorectal cancer [27], 52\% in endometrial cancer [28-30] and $4 \% \sim 12 \%$ in ovarian cancer [31]. Specifically, PIK3CA activating mutations are associated with shorter time to progression, and PTEN loss is associated with decreased survival in patients with trastuzumab-treated breast cancer [32].

In endometrial carcinoma, most PIK3CA mutations occur in exon 9 (helical domain) or exon 20 (kinase domain) [28, 33-35]. The mutations seem to differ according to histological grade, and $67 \%$ of the mutations in high-grade endometrial cancer are located in exon 20 compared with $33 \%$ in the low-grade form [33, 35]. Moreover, exon 9 and exon 20 present different mutations between type I and type II endometrial cancer. In type II cancer, exon 9 mutations have not been found, whereas exon 20 mutations have been reported in $21 \%$ of type II cases [34]. PIK3R1, which encodes another regulatory subunit of PI3K, p85a, is mutated in approximately $43 \%$ of endometrial cancer cases [36,37]. Interestingly, activation of the PI3K pathway through PIK3CA amplification and/or overexpression is likely associated with an aggressive phenotype in early-stage endometrial cancer [38]. 
In previous preclinical studies, EA was found to exert an antiangiogenesis effect, resulting in an antineoplastic function $[8,18,39]$. Wang N. et al found that EA suppressed the phosphorylation of VEGFR-2 and its tyrosine kinase activity [8] and induced downstream signaling mediators of VEGFR-2, such as AKT, ERK, JNK and eNOS. Zhao $M$ et al [18] showed that EA inhibits the markers of angiogenesis, such as COX-2, HIF1a, VEGF, VEGFR, IL-6, and IL-8, and simultaneously suppresses metastasis markers, such as MMP-2 and MMP-9, in pancreatic cancer tissue from BALB/c nude mice. Cheng et al [39] found EA could suppress COX-2, NF-kB, and Vimentin in pancreatic carcinoma PANC-1 cells in vitro and in vivo. All these data demonstrate that EA decreases tumor growth by inhibiting angiogenesis.

By using bioinformatics methods in this study, PIK3CA and PIK3R1 might be the drug targets of EA, and in vitro experiments confirmed that EA possesses antitumor activity by altering cell migration, invasion, proliferation, cell cycle and apoptosis. EA also reduced the formation of lung metastases in vivo. In addition, EA may regulate the PI3K signaling pathway to exert its antitumor effects. Currently, few targeted therapies for endometrial cancer have been developed. Monotherapy and double and triple combination chemotherapies have been previously studied, resulting in improved survival-but at the cost of tremendous toxic effects [40]. An understanding of the molecular mechanism of EA functions in endometrial cancer will lead to the development of novel and more specific compounds against key proteins in cancer, providing additional therapeutic methods. Moreover, identification of molecular markers that predict sensitivity to certain inhibitors will be helpful for the implementation of these therapeutic strategies.

In summary, this is the first study to comprehensively examine the antitumor function of EA in endometrial cancer and the targets through which EA exerts its effects. With bioinformatics analyses based on web-based databases, EA might function was found as a target inhibitor in endometrial cancer. Moreover, the function of EA was examined in endometrial cancer both in vitro and in vivo. EA is present in many fresh fruits and vegetables, and therefore, women should be encouraged to pay attention to their dietary patterns as a precaution against cancer. Furthermore, bioinformatics methods represent a new horizon for chemical compound target prediction, and these methods will be used more frequently and play a leading role in the future.

\section{Supplementary Material}

Supplementary figure.

http://www.jcancer.org/v10p3303s1.pdf

\section{Acknowledgements}

This work was supported by a grant from National Natural Science Foundation of China (Grant No.81501235).

\section{Competing Interests}

The authors have declared that no competing interest exists.

\section{References}

1. Ferlay J, Soerjomataram I, Dikshit R, Eser S, Mathers C, Rebelo M, et al. Cancer incidence and mortality worldwide: sources, methods and major patterns in GLOBOCAN 2012. International journal of cancer. 2015; 136: E359-86.

2. Bakkum-Gamez JN, Mariani A, Dowdy SC, Weaver AL, McGree ME, Martin JR, et al. Efficacy of contemporary chemotherapy in stage IIIC endometrial cancer: a histologic dichotomy. Gynecologic oncology. 2014; 132: 578-84.

3. Ilić-Stojanović S, Nikolić V, Kundaković T, Savić I, Savić-Gajić I, Jocić E, et al. Thermosensitive hydrogels for modified release of ellagic acid obtained from Alchemilla vulgaris L. extract. International Journal of Polymeric Materials and Polymeric Biomaterials. 2018; 67: 553-63.

4. Baek B, Lee SH, Kim K, Lim HW, Lim CJ. Ellagic acid plays a protective role against UV-B-induced oxidative stress by up-regulating antioxidant components in human dermal fibroblasts. The Korean journal of physiology \& pharmacology : official journal of the Korean Physiological Society and the Korean Society of Pharmacology. 2016; 20: 269-77.

5. Savic IM, Jocic E, Nikolic VD, Popsavin MM, Rakic SJ, Savic-Gajic IM. The effect of complexation with cyclodextrins on the antioxidant and antimicrobial activity of ellagic acid. Pharmaceutical development and technology. 2018: 1-9.

6. Thresiamma KC, Kuttan R. Inhibition of liver fibrosis by ellagic acid. Indian journal of physiology and pharmacology. 1996; 40: 363-6.

7. Nijhoff WA, Peters WH. Quantification of induction of rat oesophageal, gastric and pancreatic glutathione and glutathione S-transferases by dietary anticarcinogens. Carcinogenesis. 1994; 15: 1769-72.

8. Wang N, Wang ZY, Mo SL, Loo TY, Wang DM, Luo HB, et al. Ellagic acid, a phenolic compound, exerts anti-angiogenesis effects via VEGFR-2 signaling pathway in breast cancer. Breast cancer research and treatment. 2012; 134: 943-55.

9. Ceci C, Tentori L, Atzori MG, Lacal PM, Bonanno E, Scimeca M, et al. Ellagic Acid Inhibits Bladder Cancer Invasiveness and In Vivo Tumor Growth. Nutrients. 2016; 8

10. Law V, Knox C, Djoumbou Y, Jewison T, Guo AC, Liu Y, et al. DrugBank 4.0: shedding new light on drug metabolism. Nucleic acids research. 2014; 42: D1091-7.

11. Szklarczyk D, Franceschini A, Wyder S, Forslund K, Heller D, Huerta-Cepas J, et al. STRING v10: protein-protein interaction networks, integrated over the tree of life. Nucleic acids research. 2015; 43: D447-52.

12. Wang I, Vasaikar S, Shi Z, Greer M, Zhang B. WebGestalt 2017: a more comprehensive, powerful, flexible and interactive gene set enrichment analysis toolkit. Nucleic acids research. 2017.

13. Cerami E, Gao J, Dogrusoz U, Gross BE, Sumer SO, Aksoy BA, et al. The cBio cancer genomics portal: an open platform for exploring multidimensional cancer genomics data. Cancer discovery. 2012; 2: 401-4.

14. Talcott ST, Lee JH. Ellagic acid and flavonoid antioxidant content of muscadine wine and juice. Journal of agricultural and food chemistry. 2002; 50: 3186-92.

15. Zhang HM, Zhao L, Li H, Xu H, Chen WW, Tao L. Research progress on the anticarcinogenic actions and mechanisms of ellagic acid. Cancer biology \& medicine. 2014; 11: 92-100.

16. Umesalma S, Nagendraprabhu P, Sudhandiran G. Antiproliferative and apoptotic-inducing potential of ellagic acid against 1,2-dimethyl hydrazine-induced colon tumorigenesis in Wistar rats. Molecular and cellular biochemistry. 2014; 388: 157-72.

17. Naiki-Ito A, Chewonarin T, Tang M, Pitchakarn P, Kuno T, Ogawa K, et al. Ellagic acid, a component of pomegranate fruit juice, suppresses androgen-dependent prostate carcinogenesis via induction of apoptosis. The Prostate. 2015; 75: 151-60.

18. Zhao M, Tang SN, Marsh JL, Shankar S, Srivastava RK. Ellagic acid inhibits human pancreatic cancer growth in Balb c nude mice. Cancer letters. 2013; 337: 210-7.

19. Liu $Q$, Liang $X$, Niu C, Wang X. Ellagic acid promotes A549 cell apoptosis via regulating the phosphoinositide 3-kinase/protein kinase $B$ pathway. Experimental and therapeutic medicine. 2018; 16: 347-52. 
20. Shi L, Gao X, Li X, Jiang N, Luo F, Gu C, et al. Ellagic Acid Enhances the Efficacy of PI3K Inhibitor GDC-0941 in Breast Cancer Cells. Current molecular medicine. 2015; 15: 478-86.

21. Abdelazeem KNM, Singh Y, Lang F, Salker MS. Negative Effect of Ellagic Acid on Cytosolic pH Regulation and Glycolytic Flux in Human Endometrial Cancer Cells. Cellular physiology and biochemistry : international journal of experimental cellular physiology, biochemistry, and pharmacology. 2017; 41: 2374-82.

22. Markman B, Atzori F, Perez-Garcia J, Tabernero J, Baselga J. Status of PI3K inhibition and biomarker development in cancer therapeutics. Annals of oncology : official journal of the European Society for Medical Oncology. 2010; 21: 683-91.

23. Volinia S, Hiles I, Ormondroyd E, Nizetic D, Antonacci R, Rocchi M, et al. Molecular cloning, cDNA sequence, and chromosomal localization of the human phosphatidylinositol 3-kinase p110 alpha (PIK3CA) gene. Genomics. 1994; 24: 472-7.

24. Chaft JE, Arcila ME, Paik PK, Lau C, Riely GJ, Pietanza MC, et al. Coexistence of PIK3CA and other oncogene mutations in lung adenocarcinoma-rationale for comprehensive mutation profiling. Molecular cancer therapeutics. 2012; 11: 485-91.

25. Samuels $\mathrm{Y}$, Waldman T. Oncogenic mutations of PIK3CA in human cancers. Current topics in microbiology and immunology. 2010; 347: 21-41.

26. Saal LH, Holm K, Maurer M, Memeo L, Su T, Wang X, et al. PIK3CA mutations correlate with hormone receptors, node metastasis, and ERBB2, and are mutually exclusive with PTEN loss in human breast carcinoma. Cancer research. 2005; 65: 2554-9.

27. Samuels Y, Wang Z, Bardelli A, Silliman N, Ptak J, Szabo S, et al. High frequency of mutations of the PIK3CA gene in human cancers. Science (New York, NY). 2004; 304: 554

28. Oda K, Stokoe D, Taketani Y, McCormick F. High frequency of coexistent mutations of PIK3CA and PTEN genes in endometrial carcinoma. Cancer research. 2005; 65: 10669-73.

29. Hayes MP, Wang H, Espinal-Witter R, Douglas W, Solomon GJ, Baker SJ, et al. PIK3CA and PTEN mutations in uterine endometrioid carcinoma and complex atypical hyperplasia. Clinical cancer research : an official journal of the American Association for Cancer Research. 2006; 12: 5932-5.

30. Rudd ML, Price JC, Fogoros S, Godwin AK, Sgroi DC, Merino MJ, et al. A unique spectrum of somatic PIK3CA (p110alpha) mutations within primary endometrial carcinomas. Clinical cancer research : an official journal of the American Association for Cancer Research. 2011; 17: 1331-40.

31. Wang Y, Helland A, Holm R, Kristensen GB, Borresen-Dale AL. PIK3CA mutations in advanced ovarian carcinomas. Human mutation. 2005; 25: 322.

32. Razis E, Bobos M, Kotoula V, Eleftheraki AG, Kalofonos HP, Pavlakis K, et al. Evaluation of the association of PIK3CA mutations and PTEN loss with efficacy of trastuzumab therapy in metastatic breast cancer. Breast cancer research and treatment. 2011; 128: 447-56.

33. Miyake T, Yoshino K, Enomoto T, Takata T, Ugaki H, Kim A, et al. PIK3CA gene mutations and amplifications in uterine cancers, identified by methods that avoid confounding by PIK3CA pseudogene sequences. Cancer letters. 2008; 261: 120-6.

34. Catasus L, Gallardo A, Cuatrecasas M, Prat J. Concomitant PI3K-AKT and p53 alterations in endometrial carcinomas are associated with poor prognosis. Modern pathology : an official journal of the United States and Canadian Academy of Pathology, Inc. 2009; 22: 522-9.

35. Hayes MP, Douglas W, Ellenson LH. Molecular alterations of EGFR and PIK3CA in uterine serous carcinoma. Gynecologic oncology. 2009; 113: 370-3.

36. Cheung LW, Hennessy BT, Li J, Yu S, Myers AP, Djordjevic B, et al. High frequency of PIK3R1 and PIK3R2 mutations in endometrial cancer elucidates a novel mechanism for regulation of PTEN protein stability. Cancer discovery. 2011; 1: 170-85.

37. Urick ME, Rudd ML, Godwin AK, Sgroi D, Merino M, Bell DW. PIK3R1 (p85alpha) is somatically mutated at high frequency in primary endometrial cancer. Cancer research. 2011; 71: 4061-7.

38. Salvesen HB, Carter SL, Mannelqvist M, Dutt A, Getz G, Stefansson IM, et al. Integrated genomic profiling of endometrial carcinoma associates aggressive tumors with indicators of PI3 kinase activation. Proceedings of the National Academy of Sciences of the United States of America. 2009; 106: 4834-9.

39. Cheng H, Lu C, Tang R, Pan Y, Bao S, Qiu Y, et al. Ellagic acid inhibits the proliferation of human pancreatic carcinoma PANC-1 cells in vitro and in vivo. Oncotarget. 2017; 8: 12301-10.

40. Dellinger TH, Monk BJ. Systemic therapy for recurrent endometrial cancer: a review of North American trials. Expert review of anticancer therapy. 2009; 9: 905-16. 